\title{
Increasing Individual Target Glucose Levels to Prevent Hypoglycemia in Patients with Diabetes
}

\author{
Juyoung Shin ${ }^{1,2,+}$, Hyunah Kim ${ }^{3,+}$, Hun-Sung Kim ${ }^{2,4 * *}$, Churlmin Kim5, Whan-Seok Choi ${ }^{5, *}$ \\ ${ }^{1}$ Health Promotion Center, Seoul St. Mary's Hospital, Seoul, Korea \\ ${ }^{2}$ Division of Endocrinology and Metabolism, Department of Internal Medicine, Seoul St. Mary's Hospital, College of Medicine, The Catholic University \\ of Korea, Seoul, Korea \\ ${ }^{3}$ College of Pharmacy, Sookmyung Women's University, Seoul, Korea \\ ${ }^{4}$ Department of Medical Informatics, College of Medicine, The Catholic University of Korea, Seoul, Korea \\ ${ }^{5}$ Department of Family Medicine, Seoul St. Mary's Hospital, College of Medicine, The Catholic University of Korea, Seoul, Korea
}

Hypoglycemia is one of the severe complications of diabetes. To prevent hypoglycemia, an emphasis is placed on maintaining an appropriate balance between nutrition, activity, and treatment, which can be achieved by the repetition of self-trials based on self-monitoring. Clinicians routinely focus on patients' contribution, including timely intake of an adequate amount of carbohydrates, physical activity, antidiabetic medication, and abstinence from alcohol. Recently, many guidelines have highlighted the importance of clinicians' factors and recommend individualized treatments according to lifestyle patterns and specific needs following the de-intensification of treatment. The optimal value of hemoglobin Alc (HbAlc) levels for blood glucose level regulation remains controversial among countries, but it generally does not exceed $8.0 \%$. In populations that are at a risk of hypoglycemia, such as the older adults, it is advisable to adjust the target blood glucose level to less than $8.0 \%$. Meanwhile, a blood glucose level of 7.0\%-7.5\% is generally recommended for healthy older adults. If the expected lifetime is shorter than 10 years or in patients with chronic kidney disease and severe cardiovascular disease, the HbAlc level target can be increased to $7.5 \%-8.0 \%$. For even shorter lifetime expectancy, the target can be adjusted up to $8.0 \%-9.0 \%$. To prevent hypoglycemia, the target blood glucose level needs to be adjusted, particularly in older adult patients. Ultimately, it is important to identify the maximum blood glucose levels that do not cause hypoglycemia and the minimum blood glucose levels that do not cause hyperglycemia-associated complications.

Keywords: Diabetes Mellitus; Hypoglycemia; Hemoglobin Alc

Received: December 12, 2019, Accepted: December 13, 2019

*Corresponding Author: Whan-Seok Choi https://orcid.org/0000-0001-8978-9885

Tel: +82-2-2258-8262, Fax: +82-2-2258-8297,E-mail: fmchs@catholic.ac.kr

*Corresponding Author: Hun-Sung Kim https://orcid.org/0000-0002-7002-7300

Tel: +82-2-2258-8262, Fax: +82-2-2258-8297, E-mail: 01cadiz@hanmail.net

*These two corresponding authors contributed equally to this work.

tThese two authors as co-first authors contributed equally to this work. 


\section{INTRODUCTION}

The Korean Diabetes Association (KDA) recommends an hemoglobin Alc (HbAlc) level of $<6.5 \%$ as the general goal of blood glucose level management. ${ }^{1-8)}$ Most guidelines, such as those of the American Diabetes Association (ADA), ${ }^{9-14)}$ American Association of Clinical Endocrinologists (AACE) ${ }^{15)}$ European Association for the Study of Diabetes (EASD), ${ }^{16)}$ and International Diabetes Federation (IDF), ${ }^{17,18)}$ recommend an $\mathrm{HbAlc}$ level of $<7.0 \%$ based on the stipulation that lowering the $\mathrm{HbAlc}$ level to its normal range reduces the risk of diabetes mellitus (DM)-associated complications. Some doctors often perceive this value as an absolute target for hyperglycemic control, but it is not. In certain conditions, lowering the HbAlc level to a general target level would do more harm than good. Various studies reported an increased risk of hypoglycemia, weight gain, and cardiovascular disease from active treatment. ${ }^{19-21)}$ Strict blood glucose level management in the early stages of diabetes helps to reduce the incidence of complications. However, for patients with longer periods of diabetes who already developed cardiovascular disease, active intensive blood glucose level management considerably increases the risk of hypoglycemia, cardiovascular disease, and mortality, rather than prevent complications. Therefore, the ADA, AACE, EASD, IDF, Japan Diabetes Society (JDS), and KDA have developed various strategies to prevent hypoglycemia. ${ }^{9-18,22-24)}$ Grossly, it is important to eat a well-balanced diet, perform regular exercise, and take appropriate medication to prevent hypoglycemia. In addition, individualized target goal is recommended according to lifestyle patterns and specific needs.

\section{EDUCATION}

Nothing is better than prevention, and most hypoglycemic events are preventable. For that, it is important to educate both patients and their family, who should be informed about the possible causes of hypoglycemia and preventive strategies, regarding the risk of hypoglycemia. Previous studies suggest that the common causes are dietary factors, excessive physical activity, stress, and medication misadventures. ${ }^{25)} \mathrm{It}$ is necessary to determine the effect of carbohydrate intake, physical activity, and use of antidiabetic medications on blood glucose level. A comprehensive strategy for proper balance of nutrition, activity, and medication is needed to prevent hypoglycemia. Although newer antidiabetic medications are less dependent on mealtime, moderate amount of carbohydrate intake on regular mealtime is generally an important nutritional management for diabetic patients. Carbohydrate counting is useful especially for patients receiving rapid-acting insulin treatment. This technique may require the adjustment of food intake and/or antidiabetic medications before performing physical activities or sleeping to prevent hypoglycemia. Appropriate balance between nutrition, activity, and treatment can be achieved by repetition of selftrials based on self-monitoring.

Patients should pay attention to nocturnal hypoglycemia as more than $50 \%$ of cases of severe hypoglycemia occur at night. ${ }^{26)}$ Regardless of whether or not blood glucose levels are well controlled, patients should consult their doctors if nocturnal hypoglycemia occurs frequently. The target blood glucose levels for those with or without nocturnal hypoglycemia are yet to be established. Regular consumption of snacks to prevent nocturnal hypoglycemia in patients with type $1 \mathrm{DM}$ is not recommended. ${ }^{27)}$ In patients who take medications for diabetes control twice daily, severe hypoglycemia can occur at dawn if they eat dinner early or consume insufficient protein at dinner; thus, taking snacks before bedtime is recommended. Patients with blood glucose levels of 100-140 mg/dL are advised to measure their blood glucose levels before bedtime. Those with lower blood glucose levels $(<100$ $\mathrm{mg} / \mathrm{dL}$ ) before bedtime are recommended to eat snacks containing glucose and protein (e.g., one glass of milk and half a banana) before bedtime. $^{28)}$

Blood glucose level regulation also remains important in patients with a history of chronic alcohol consumption or those who are intermittent heavy drinkers. ${ }^{29)}$ Alcohol intake is absorbed in the stomach and intestines, which can interfere with the metabolism of other nutrients and cause hypoglycemia by blocking gluconeogenesis. Drinking alcohol on an empty stomach or immediately after exercise can cause hypoglycemia. Patients with diabetes are advised to abstain from drinking alcohol, but those who cannot are recommended to only drink alcohol once or twice weekly after meals and only 1 or 2 glasses at a time. ${ }^{30)}$ The recommendations for alcohol consumption to reduce the risk of hypoglycemia related to alcohol drinking in those with diabetes are shown in Table $1 .^{31)}$

\section{INDIVIDUALIZED GLUCOSE TARGET}

There is no rationale to deliberately avoid active blood glucose level management in patients without severe cardiovascular disease or those with risk of hypoglycemia or other adverse conditions. If it is safe and appropriate to use oral hypoglycemic agents (OHA) or insulin, targeting an $\mathrm{HbAlc}$ level of $<6.5 \%$ of would help prevent microvascular and macrovascular complications. In contrast, in patients with advanced age, history of severe hypoglycemia, short life expectancy, renal disease, macrovascular complications, severe illnesses, or type 2 DM who cannot achieve an HbAlc level of $<6.5 \%$ without intensive care, it is reasonable to increase the blood glucose level target and to provide a safe line to use the reduced doses of OHA or insulin without

Table 1. Recommendations to reduce alcohol drinking-related hypoglycemia ${ }^{31)}$

\begin{tabular}{cc}
\hline No. & Recommendations \\
\hline 1 & $\begin{array}{c}\text { Do not drink alcohol before meals, particularly after a fast. Consume } \\
\text { carbohydrate-rich foods before drinking. }\end{array}$ \\
2 & Alcohol cannot replace the recommended carbohydrate intake. \\
3 & Consume sufficient amounts of water. \\
4 & Check your blood glucose level before bedtime when drinking alcohol earlier \\
in the day. Make sure your blood glucose level is maintained at 100-140 \\
mg/dL.
\end{tabular}


overtreatment. In particular, if there are no hyperglycemia symptoms, such as polyphagia, polydipsia, or polyuria, it is reasonable to increase the $\mathrm{HbAlc}$ level target. If the life expectancy is shorter than 10 years, the HbAlc level target could be $7.5 \%-8.0 \%$. If there are comorbidities such as cognitive disorder, chronic kidney disease, and severe cardiovascular disease, an HbAlc level of $\leq 8.0 \%$ is recommended. The JDS also states that although the general target for HbAlc level is $<7.0 \%$, treatment targets should be individualized to $<8.0 \%$ if there is a risk for hypoglycemia. ${ }^{22-24)}$ The American College of Physicians stated that the standard HbAlc level of $<7.0 \%$ recommended by the Institute for Clinical Systems Improvement increases the risk of death, weight gain, hypoglycemia, and other adverse events and does not reduce the mortality rate. ${ }^{32)}$ Despite the differences in the recommended levels, the common recommendation of professional diabetes societies is that the optimal HbAlc level goal should be increased in patients with high risk of hypoglycemia.

Older adult patients with diabetes are at an increased risk of hypoglycemia because they are more vulnerable to malnutrition due to anorexia, experience difficulty in masticating or swallowing, and have digestive disorders. Thus, it is important to monitor the risk of hypoglycemia due to insufficient food intake when caring for older patients with diabetes. In addition, physiological and cognitive functions, lifestyle patterns, and risks of hypoglycemia should be assessed in this population, and treatment goals should be individualized. Treatment goals are set to assess the effects of long-term blood glucose level management. If the patient is active and has no cognitive impairment, the goal of blood glucose level management can be similar to that of other young patients. However, if patients have advanced diabetes complications, a short life expectancy, or serious cognitive and functional disorders, blood glucose level control should be enforced less strictly. The American Geriatric Society recommends an HbAlc level of 7.5\%$8.0 \%$ in the general patient population, $7.0 \%-7.5 \%$ in healthy patients, and $8.0 \%-9.0 \%$ in those with a short life expectancy. ${ }^{33)}$ Despite these varying targets, hyperglycemia that may cause diabetes symptoms or acute complications should be avoided in all cases. The IDF generally recommends that physicians should carefully monitor hypoglycemia in patients with a fasting blood glucose level of $<110 \mathrm{mg} / \mathrm{dL}$ and an HbAlc level of $<7 \%{ }^{17,18)}$ In such patients, the physician should prescribe drugs with a low risk of hypoglycemia. Moreover, all patients who take insulin or hypoglycemia-causing diabetic drugs should measure their blood glucose levels regularly, create emergency contacts, and develop a treatment plan for hypoglycemia. The JDS also recommended that in older patients, the lower limit of HbAlc level should be increased to $6.5 \%-7.5 \%$ depending on their cognitive function or their performance of daily living activities. ${ }^{22-24)}$

Blood glucose levels tend to be more strictly controlled in hospitalized patients or those with severe conditions, but glucose control can increase the risk of hypoglycemia. ${ }^{33)}$ Intensive blood glucose level management during hospitalization is routine clinical practice, but it increases the risk of death from hypoglycemia. Therefore, the blood glucose of inpatients is not targeted at $80-100 \mathrm{mg} / \mathrm{dL}$. Moreover, the
Table 2. Inpatient risk factors for hypoglycemia ${ }^{34)}$

\begin{tabular}{cl} 
No. & \multicolumn{1}{c}{ Inpatient risk factors for hypoglycemia } \\
\hline 1 & Inappropriate use of insulin \\
& - Dose and injection \\
& - Errors in mixing medications \\
2 & Inappropriate diet and time for taking antidiabetic medications \\
3 & Nutritional state change \\
& - Intravenous feeding \\
& - Carbohydrate intake \\
& - Fasting and eating time and changes in snack consumption \\
& - Loss of appetite \\
4 & - Vomiting \\
5 & Discontinuing steroid treatment or dose change \\
6 & Acute disease/recovery from stress/illness \\
7 & Limitations in activities of daily living after illness \\
& Limb amputation
\end{tabular}

preprandial blood glucose level is generally set to $<140 \mathrm{mg} / \mathrm{dL}$, and the random blood glucose level is $<180 \mathrm{mg} / \mathrm{dL}$. For patients with severe underlying disease, the target blood glucose level is $140-180 \mathrm{mg} / \mathrm{dL}$. If the life expectancy is shorter or the patient has terminal disease, the blood glucose level control target should be enforced less strictly (Table 2). ${ }^{34)}$

\section{SELECTION OF TREATMENT}

A more effective and simple way to prevent hypoglycemia is to reconsider antidiabetic medications. ${ }^{35)}$ Though the harm of intensive treatment would exceed the benefits for those with high risk of hypoglycemia, most of them were treated with insulin or sulfonylureas, which are the most common medication causing hypoglycemia. ${ }^{36)}$ The selection of medications should be based on the overall patient condition, including audiovisual disorders, malnutrition, muscle loss, cognitive and emotional functions, physical functions, and concomitant treatment. Older adults or patients with advanced renal or hepatic diseases and dementia are prone to hypoglycemia due to poor kidney or liver function, irregular meal consumption, and drug interactions from multidrug treatment. Hence, it is reasonable to de-intensify antidiabetic treatment, simplify treatment regimens, or use other medications with relatively low risk of hypoglycemia. Moreover, insulin and OHA should be started at low doses and gradually increased.

\section{CONCLUSION}

The ADA, AACE, EASD, IDF, JDA, and KDA have developed various strategies to prevent hypoglycemia, including increasing the target blood glucose level in patients with high risk of hypoglycemia. ${ }^{9-18,22-24)}$ Strategies focus not only on patients' factors such as moderate meal intake, consumption of snacks during exercise and before bedtime to prevent hypoglycemia, and abstinence from alcohol but also clinicians' factor such as individualized treatment goal and prescription according to lifestyle patterns and specific needs. Most members of the diabetes healthcare team are only aware of the general goals of 
blood glucose level management and are often unfamiliar with the adjustment of blood glucose level targets. In clinical practice, blood glucose level targets are often increased based on experience rather than any systematic basis. ${ }^{37}$ Clinicians should identify the maximum level of blood glucose level that will not cause hypoglycemia-related complications. Our future studies are aimed at developing a systematic basis for such adjustments.

\section{CONFLICT OF INTEREST}

No potential conflict of interest relevant to this article was reported.

\section{ACKNOWLEDGMENTS}

This research was supported by a grant from the Korea Institute of Drug Safety and Risk Management in 2018.

\section{ORCID}

Juyoung Shin: https://orcid.org/0000-0002-5284-7794

Hyunah Kim: https://orcid.org/0000-0002-5533-2040

Hun-Sung Kim: https://orcid.org/0000-0002-7002-7300

Churlmin Kim: https://orcid.org/0000-0001-9974-3709

Whan-Seok Choi: https://orcid.org/0000-0001-8978-9885

\section{REFERENCES}

1. Ko SH, Hur KY, Rhee SY, Kim NH, Moon MK, Park SO, et al. Antihyperglycemic agent therapy for adult patients with type 2 diabetes mellitus 2017: a position statement of the Korean Diabetes Association. Korean J Intern Med 2017;32:947-58.

2. Ko SH, Hur KY, Rhee SY, Kim NH, Moon MK, Park SO, et al. Antihyperglycemic agent therapy for adult patients with type 2 diabetes mellitus 2017: a position statement of the Korean Diabetes Association. Diabetes Metab J 2017;41:337-48.

3. Lee BW, Kim JH, Ko SH, Hur KY, Kim NH, Rhee SY, et al. Insulin therapy for adult patients with type 2 diabetes mellitus: a position statement of the Korean Diabetes Association, 2017. Korean J Intern Med 2017; 32:967-73.

4. Lee BW, Kim JH, Ko SH, Hur KY, Kim NH, Rhee SY, et al. Insulin therapy for adult patients with type 2 diabetes mellitus: a position statement of the Korean Diabetes Association, 2017. Diabetes Metab J 2017;41: 367-73.

5. Moon MK, Hur KY, Ko SH, Park SO, Lee BW, Kim JH, et al. Combination therapy of oral hypoglycemic agents in patients with type 2 diabetes mellitus. Diabetes Metab J 2017;41:357-66.

6. Moon MK, Hur KY, Ko SH, Park SO, Lee BW, Kim JH, et al. Combination therapy of oral hypoglycemic agents in patients with type 2 diabetes mellitus. Korean J Intern Med 2017;32:974-83.

7. Rhee SY, Kim HJ, Ko SH, Hur KY, Kim NH, Moon MK, et al. Monotherapy in patients with type 2 diabetes mellitus. Korean J Intern Med 2017;32:959-66.

8. Rhee SY, Kim HJ, Ko SH, Hur KY, Kim NH, Moon MK, et al. Monother- apy in patients with type 2 diabetes mellitus. Diabetes Metab J 2017;41: 349-56.

9. American Diabetes Association. Standards of medical care in diabetes: 2019 abridged for primary care providers. Clin Diabetes 2019;37: 11-34.

10. American Diabetes Association. 6. Glycemic targets: standards of medical care in diabetes-2019. Diabetes Care 2019;42(Suppl 1):S6170.

11. American Diabetes Association. 9. Pharmacologic approaches to glycemic treatment: standards of medical care in diabetes-2019. Diabetes Care 2019;42(Suppl 1):S90-102.

12. American Diabetes Association. 12. Older adults: standards of medical care in diabetes-2019. Diabetes Care 2019;42(Suppl 1):S139-47.

13. Summary of revisions: standards of medical care in diabetes-2019. Diabetes Care 2019;42(Suppl 1):S4-6.

14. Neumiller JJ, Umpierrez GE. 2018 Standards of care update: pharmacologic approaches to glycemic management in people with type $2 \mathrm{di}-$ abetes. Diabetes Spectr 2018;31:254-60.

15. Garber AJ, Abrahamson MJ, Barzilay JI, Blonde L, Bloomgarden ZT, Bush MA, et al. Consensus statement by the American Association of Clinical Endocrinologists and American College Of Endocrinology on the comprehensive type 2 diabetes management algorithm: 2018 executive summary. Endocr Pract 2018;24:91-120.

16. McGuire H, Longson D, Adler A, Farmer A, Lewin I; Guideline Development Group. Management of type 2 diabetes in adults: summary of updated NICE guidance. BMJ 2016;353:i1575.

17. Ceriello A, Colagiuri S. International Diabetes Federation guideline for management of postmeal glucose: a review of recommendations. Diabet Med 2008;25:1151-6.

18. Dunning T, Sinclair A, Colagiuri S. New IDF guideline for managing type 2 diabetes in older people. Diabetes Res Clin Pract 2014;103:53840.

19. Action to Control Cardiovascular Risk in Diabetes Study Group, Gerstein HC, Miller ME, Byington RP, Goff DC Jr, Bigger JT, et al. Effects of intensive glucose lowering in type 2 diabetes. N Engl J Med 2008;358: 2545-59.

20. ADVANCE Collaborative Group, Patel A, MacMahon S, Chalmers J, Neal B, Billot L, et al. Intensive blood glucose control and vascular outcomes in patients with type 2 diabetes. N Engl J Med 2008;358: 2560-72.

21. Duckworth W, Abraira C, Moritz T, Reda D, Emanuele N, Reaven PD, et al. Glucose control and vascular complications in veterans with type 2 diabetes. N Engl J Med 2009;360:129-39.

22. Araki E, Haneda M, Kasuga M, Nishikawa T, Kondo T, Ueki K, et al. New glycemic targets for patients with diabetes from the Japan Diabetes Society. J Diabetes Investig 2017;8:123-5.

23. Haneda M, Noda M, Origasa H, Noto H, Yabe D, Fujita Y, et al. Japanese Clinical Practice Guideline for Diabetes 2016. Diabetol Int 2018;9:1-45.

24. Namba M, Iwakura T, Nishimura R, Akazawa K, Matsuhisa M, Atsumi $\mathrm{Y}$, et al. The current status of treatment-related severe hypoglycemia in Japanese patients with diabetes mellitus: a report from the committee on a survey of severe hypoglycemia in the Japan Diabetes Society. Diabetol Int 2018;9:84-99.

25. Mitchell BD, Vietri J, Zagar A, Curtis B, Reaney M. Hypoglycaemic 
events in patients with type 2 diabetes in the United Kingdom: associations with patient-reported outcomes and self-reported HbAlc. BMC Endocr Disord 2013;13:59.

26. Unger J, Parkin C. Hypoglycemia in insulin-treated diabetes: a case for increased vigilance. Postgrad Med 2011;123:81-91.

27. Saleh TY, Cryer PE. Alanine and terbutaline in the prevention of nocturnal hypoglycemia in IDDM. Diabetes Care 1997;20:1231-6.

28. McCall AL. Insulin therapy and hypoglycemia. Endocrinol Metab Clin North Am 2012;41:57-87.

29. Lee S, Kim JS, Jung JG, Oh MK, Chung TH, Kim J. Korean alcohol guidelines for moderate drinking based on facial flushing. Korean J Fam Med 2019;40:204-11.

30. Committee of Clinical Practice Guideline, Korean Diabetes Association. Treatment guideline for diabetes. J Korean Diabetes 2011; 12(Suppl 1):52-6.

31. Cho DH. Blood sugar control in alcohol-consuming diabetics. J Korean Diabetes 2012;13:91-4.

32. Qaseem A, Wilt TJ, Kansagara D, Horwitch C, Barry MJ, Forciea MA, et al. Hemoglobin Alc targets for glycemic control with pharmacologic therapy for nonpregnant adults with type 2 diabetes mellitus: a guid- ance statement update from the American College of Physicians. Ann Intern Med 2018;168:569-76.

33. Hulkower RD, Pollack RM, Zonszein J. Understanding hypoglycemia in hospitalized patients. Diabetes Manag (Lond) 2014;4:165-76.

34. AGS Choosing Wisely Workgroup. American Geriatrics Society identifies five things that healthcare providers and patients should question. J Am Geriatr Soc 2013;61:622-31.

35. Sussman JB, Kerr EA, Saini SD, Holleman RG, Klamerus ML, Min LC, et al. Rates of deintensification of blood pressure and glycemic medication treatment based on levels of control and life expectancy in older patients with diabetes mellitus. JAMA Intern Med 2015;175:1942-9.

36. Kim YS, Cho BL, Kim WS, Kim SH, Jung IH, Sin WY, et al. Frequency and severity of hypoglycemia in type 2 diabetes mellitus patients treated with a sulfonylurea-based regimen at university-affiliated hospitals in Korea: the naturalistic evaluation of hypoglycemic events in diabetic subjects study. Korean J Fam Med 2019;40:212-9.

37. Chan KT, Kobayashi KM, Roy A, Fuller-Thomson E. Diabetes care of non-obese Korean Americans: considerable room for improvement. Korean J Fam Med 2019;40:72-9. 